\title{
Design and Expansion of Gearbox for Multi-Purpose Milling Machine
}

Pulluru Nagarajareddy ${ }^{1}$

P.G Student,

Department of Mechanical Engineering,

VEMU Institute of Technology, P. Kothakota, Pakala, Chittoor Dist, A.P. ${ }^{1}$

Ganta Suresh ${ }^{2}$

Associate Professor,

Department of Mechanical Engineering,

VEMU Institute of Technology, P. Kothakota, Pakala, Chittoor Dist, A.P. ${ }^{2}$

\begin{abstract}
Now days Milling and drilling operations not uniquely did on single machine. To avoid this confusion of doing manufacturing operations a small difference in gear box design may give a single option solution to the manufacturers. A liver based shifter used as a differential to change gear systems to perform these two different operations on a single machine. On the proposed above operations torque generation will play an important role. From the survey taken before thesis base papers it is observed that low torque is good for milling and high torque is good for drilling. Gear box outline will be same for casing to avoid machine space and change in gear alignment by addition of a shifter to perform good results for drilling and milling.
\end{abstract}

Angle drilling is one of the major time taking processes in large scale production industries. To overcome such deviation special purpose radial drilling with milling attachments introducing in market. Present paper is a partial fulfillment to the present market needs to understand the variations in machine design accessories.

Gear design and gear ratios are theoretically calculated and the whole gear alignment performed in design software creo 3.0. Simulations and stress analysis and torque generation graphs have been generated by using ANSYS work bench 15.0. L18 Taguchi orthogonal array on torque generated and spindle RPM on these cases has been submitted.

Total design will be analyses by using finite element analysis in terms of torque applicable at each point with different speed ratios on different materials. Simulations on each material will be submitted with torque applications and performance comparison with before designs of general purpose machines. The alignment will be in two stages with torque increasing for drilling and torque decreasing for milling operation, alignment of gear box will be changes by using lever.

Keywords: gear alignments, speed reduction, design of reduction gear box, FEA.

\section{INTRODUCTION}

A radial load, or overhung load (OHL) as it is also called, is a bending force imposed on a shaft due to the torque transmitted by belt drives, chain drives, or gears. Radial forces can also be created by belt or chain tension and by a misaligned shaft coupling.

\author{
M. Dorababu 3 \\ Assistant Professor, \\ Department of Mechanical Engineering, \\ VEMU Institute of Technology, P. Kothakota, \\ Pakala, Chittoor Dist, A.P. ${ }^{3}$ \\ Dr. Ganugapenta Ramesh ${ }^{4}$ \\ Associate Professor, \\ Dept.of Mechanical Engineering, \\ Vemu institute of Technology, Chittoor, Ap, India ${ }^{4}$.
}

The purpose of a gear reduction system is to convert input an speed and torque into a different output speed and torque. The design at hand requires the use of two gears whose diameters are specified at 24 and 12 inches each. These gears are attached to a shaft whose diameter is specified at two inches, and the bearings, keys, gears, speeds, safety factors, etc need to be determined from statics, strengths, fatigue, and various other design considerations.

Along with torque overloading and shock loading, excessive radial loading (overhang load) is one of the top reasons for gearboxes fail. It is also one of the least considered elements when integrating speed reducers with gear, belt, and sprocket drive systems for tools, rolling mills and transmitting machinery. Toothed gears are used to change the speed and power ratio as well as direction between an input and output shaft. Gears are the most common means of transmitting motion and power in the modern mechanical engineering world. They form vital elements of mechanisms in many machines such as automobiles, metal cutting machine.

\section{TYPES OF GEARS}

There are many different types of gears used by industry, but all these gears share the same purpose, which is to transmit motion from one shaft to another. Generally, gearing consists of a pair of gears with axes are either perpendicular or parallel . Among all the gears in the world, the four most generally discussed gears are spur gear, helical gear, bevel gear, and worm gearing.

Spur gears considered as the simplest form of gearing, and they consist of teeth parallel to the axis of rotation. The common pressure angles used for spur gears are $141 / 2,20$, and 25 degrees. One of the advantages of a low pressure angle is smoother and quieter tooth action. In contrast, larger pressure angles have the advantages of better load carrying capacity.

Helical gears consist of teeth that are cut at an angle and inclined with the axis of rotation. Helical gears essentially have the same applications as spur gears. However, because of their gradual engagement of the teeth during meshing, helical 
gears tend to be less noisy. In addition, the inclined tooth develops thrust loads and bending couples, which are not present in the spur gear.

Bevel gears teeth are formed on conical surfaces and unlike spur and helical gears, bevel gears are used for transmitting motion between intersecting shafts not parallel shafts. There are different types of bevel gears, but all of them establish thrust, radial, and tangential loads on their support bearings.

Worm gearing consists of the worm and worm gear. Depend upon the rotation direction of the worm; the direction of rotation of the worm gear would be different. The direction of rotation also depends upon whether the worm teeth are cut left-hand or right-hand. In general, worm gear sets are more efficient when the speed ratios of the two shafts are high. Basically, in worm gearing, higher speed equals to better efficiency. The following figure demonstrates the four most common types of gears in industry.

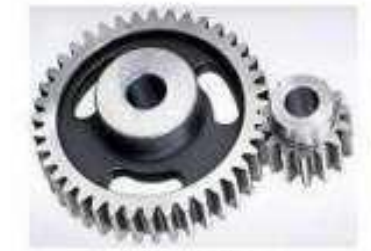

a. Spur Gears

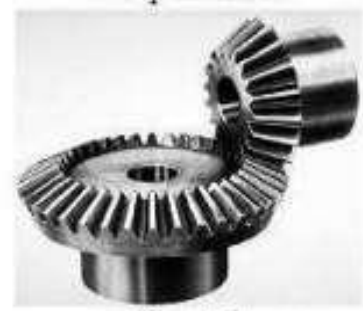

c. Bevel Gears

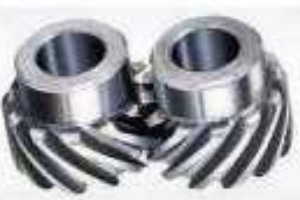

b. Helical Gears

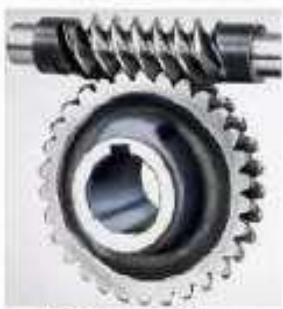

d. Worm Gears
Manufacturing processes A number of ways can be used to manufacture the shape of the gear teeth; however, they can be classified into two categories - Forming and Generating. In forming processes, the tooth space takes the exact form of the cutter. On the other hand, generating is a process that uses a tool having a shape different from the tooth profile which is moved relative to the gear blank as to obtain the proper tooth shape. The same theoretical tooth forms can be produced by both forming and generating, but the actual profiles that result on the parts differ slightly. Generated profiles are actually a series of flats whose envelope is the desired form, while the surface of a formed profile is usually a continuous curve. In general, gear teeth may be machined by milling, shaping, or hobbing. Also, they may be finished by shaving, burnishing, grinding, or lapping.

Milling - a form milling cutter will be used to conform the tooth space. The tooth form is produced by passing the milling cutter with the appropriate shape through the blank. The only drawback for this method is the necessity to use a different cutter for each gear because different gears have differentshaped tooth spaces. Shaping - either a pinion cutter or a rack cutter will be used to generate the gear teeth. The cutter reciprocates with respect to the work and is fed into the gear bank. Since each tooth of the cutter is a cutting tool, the teeth are all cut after the blank has completed one rotation.

Hobbing - one of the fastest ways of cutting gears. The hob basically is a cutting tool that is shaped like a worm. As the hob rotates and feeds along the gear axis, the gear rotates about its axis in a carefully controlled environment. A single hob of a given normal pitch and pressure angle can be used to produce any standard external spur or helical gear with the same pitch and pressure angle. Finishing - if there are errors in the tooth profiles, gears may be subjected toadditional dynamic forces. A good finishing on tooth profiles would help to diminish these errors. Shaving machines offer to cut off a small amount of metal and improve the accuracy of the tooth profile. Burnishing utilizes hardened gears with slightly oversized teeth and run in mesh with the gear until the surfaces become smooth. Grinding employs the principle of generating and produces very accurate gear teeth.

Lapping is applied to heat treated gears to correct small errors, improve surface finish, and remove nicks and burrs.

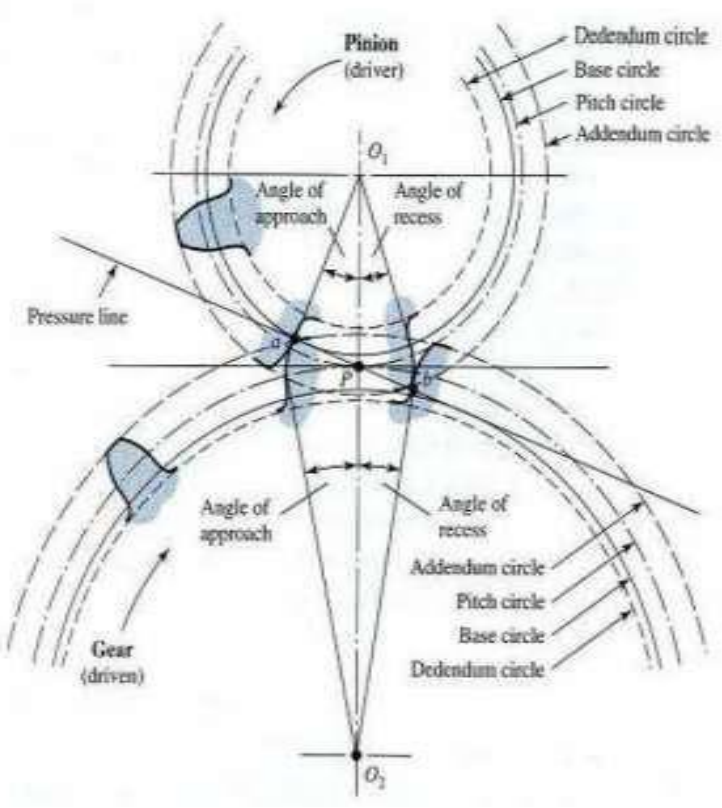

Tooth action

The classification of feed gearboxes according to the type of mechanism used to change the rate of feed is as follows:

1. Feed gearboxes with pick-off gears. Used in batchproduction machine tools with infrequent

Change over from job to job, such as automatic, semiautomatic, single-purpose, and special purpose machine tools. These

gearboxes are simple in design and are similar to those used for speed changing 
2. Feed gearboxes with sliding gears. These gearboxes are widely used in general-purpose machine tools, transmit high torques, and operate at high speeds. Figure shows a typical gearbox that provides four different ratios. Accordingly, gears $\mathrm{Z} 2, \mathrm{Z} 4, \mathrm{Z6}$, and $\mathrm{Z} 8$ are keyed to the drive shaft and mesh, respectively, with gears $\mathrm{Z1}, \mathrm{Z} 3, \mathrm{Z5}$, and $\mathrm{Z7}$, which are mounted freely on the driven key shaft. The sliding key engages any gear on the driven shaft. The engaged gear transmits the motion to the driven shaft while the rest of the gears remain idle. The main drawbacks of

such feed boxes are the power loss and wear occurring due to the rotation of idle gears and insufficient rigidity of the sliding key shaft. Feed boxes with sliding gears are used in small- and medium-size drilling machines and turret lathes.

Norton gearboxes. These gearboxes provide an arithmetic series of feed steps that is suitable for cutting threads and so are widely used in engine lathe feed gearboxes as shown in FIG

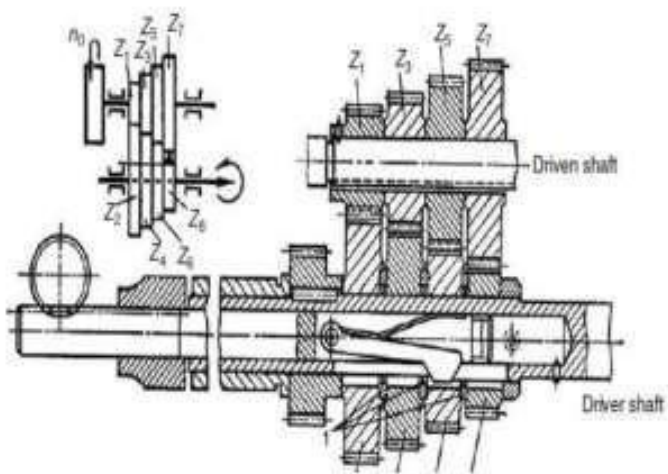

For a frame of reference, any, tøoth of interest on an analysis gear is usually oriented at the top of the gear and the mating gear is located on top of the gear of interest.

Standard gear diagram showing the analysis gear below and the mating gear above it. The base plane projection of this helical gear pair is shown above the mating gears.

\section{INTRODUCTION TO TAGUCHI METHOD}

The need for selecting and implementing optimal machining conditions and the most suitable cutting tool has been felt over the last few decades. In machining, the speed and motion of the cutting tool is specified

through several parameters. These parameters are selected for each operation based upon the work piece material, tool material, tool size, and more. Machining parameters that can affect the processes are:

a) Cutting speed - The speed of the work piece surface relative to the edge of the cutting tool during a cut, The cutting speed is measured in meter per minute, b) Feed rate - The speed of the cutting tool's movement relative to the work piece as the tool makes a cut. The feed rate is measured in $\mathrm{mm}$ per revolution. c) Depth of cut - The depth of the tool along the radius of the work piece as it makes a cut, as in a turning or boring operation. A large depth of cut will require a low feed rate, or else it will result in a high load on the tool and reduce the tool life. Therefore, a feature is often machined in several steps as the tool moves over at the depth of cut. The Taguchi method is a well-known technique that provides a systematic and efficient methodology for process optimization and this is a powerful tool for the design of high quality systems.

\section{LITERATURE SURVEY}

In 2001, Howard [1] simplified the dynamic gear model to explore the effect of friction on the resultant gear case vibration. The model which incorporates the effect of variation in gear tooth torsional mesh stiffness, was developed using finite element analysis, as the gears mesh together. The method of introducing the frictional force between teeth into the dynamic equations is given in his paper. The comparison between the results with friction and without friction was investigated using Matlab and Simulink models developed from the differential equations

In 2003, Wang [2] surveyed the nonlinear vibration of gear transmission systems. The progress in nonlinear dynamics of gear driven system is reviewed, especially the gear dynamic behavior by considering the backlash and time-varying mesh stiffness of teeth. The basic concepts, the mathematical models and the solution methods for non-linear dynamics of geared systems were all reviewed in his paper.

In 1999, Kelenz [3] investigated a spur gear set using FEM. The contact stresses were examined using a two dimensional FEM model. The bending stress analysis was performed on different thin rimmed gears. The contact stress and bending stress

comparisons were given in his studies.

Randall and Kelley [4 modifications have been made to Sweeney's basic model to extend it to higher quality gears where the tooth deflection component is more 15 important. The tooth deflection compliance matrix and the contact compliance vector have been derived using finite element models. The effects on the transmission error of the variation of the tooth body stiffness with the load application point have been investigated, and a simulation program for transmission error (TE) computation with varying stiffness has been developed. In order to study the case where the tooth deflection component is the dominant source of the transmission error nylon gears were used. All the simulation results have been compared with the measured transmission errors from a single-stage gearbox.

In 1996, Sweeney [5] developed a systematic method of calculating the static transmission error of a gear set, based on the effects of geometric parameter variation on the transmission error. He assumed that the tooth (pair) stiffness is constant along the line of action (thin-slice model) and that the contact radius for calculation of Hertzian deformation is the average radius of the two profiles in contact. Sweeney's model 
is applicable to cases where the dominant source of transmission error is geometric imperfections, and is particularly suited to automotive quality gear analysis. The results

of his model gave very good agreement with measurements on automotive quality gears. Cornell et al. (1978) [6] presented a solution for a dynamic model of spur gear systems for all practical contact ratios. The dynamic response of the gear system and the associated tooth loads and stressing were determined in this analysis. The dynamic model considered the two gears as a rigid inertia and the teeth act a variable spring of a dynamic system which was excited by the meshing action of the teeth. The effects of different parameters like nonlinearity of the tooth pair stiffness in meshing, the tooth

errors and the tooth profile modifications were included in this study. It concluded that system inertia and damping, tooth profile modification and system critical speeds affect the dynamic gear tooth loads and stressing dominantly.

J.W.Lund (1978) [7] described method for calculating the coupled torsional-lateral vibrations in a geared system of rotors. In this paper both forced vibrations and free damped vibrations whose complex Eigen frequencies define the damped criticalspeeds and the stability of the rotor system were considered. The Holzer method was used for torsional vibrations and the Myklestad Prohl method was used for lateral vibrations, after which they were coupled through impedance matching at the gear meshes.

Ozguven et al. (1988) [8] used single degree of freedom nonlinear model for the dynamic analysis of gear pair. Calculations for the dynamic mesh and tooth forces, dynamic factors based on stresses and dynamic transmission error from measured or calculated loaded static transmission errors were performed by two methods and a

computer program was developed. The effects of variable mesh stiffness and damping, gear errors pitch, profile errors, run out errors, profile modifications and backlash were also discussed in this analysis. One of the methods was accurate and the other one was approximate. In the first method, the time variation of both mesh stiffness and damping was demonstrated with numerical examples. In the second method, the time average of the mesh stiffness was used. However, the excitation effect of the variable mesh stiffness was included in the formulation used in approximate analysis. It was concluded from the comparison of the results of the two methods that the displacement excitation resulting from variable mesh stiffness was more important than the change in system natural frequency resulting from the mesh stiffness variation.

Parker et al. (2000) [9] investigated dynamic response of a spur gear pair using a Finite element/contact mechanics model which suits well for dynamic gear analyses. The gear pair was tested across a wide range of operating speeds and torques. Comparisons were made with other researcher's published gears taken fromRadial drilling machine. experiments that reveal complex non-linear phenomena. The non-linearity in meshing was due to the contact loss of the meshing teeth. It occurs even for large torques for highprecision gears also. Dynamic mesh forces were calculated using a detailed contact analysis at each time step as the gears roll through the mesh. Mesh forces are Page 10 determined by contact analysis in combination with a unique semi-analytica

\section{METHODOLOGY}

New advances in computer technology have made finite element stress analysis a routine tool in design process has given rise to computer-aided design (CAD) using solid-body modeling. Some benefits of CAD are productivity improvement in design, shorter lead times in design, more logical design process \& analysis, fewer design errors, greater accuracy in design calculations,

standardization of design, more understandability and improved procedures for engineering changes.

\section{Finite Element Analysis (FEA)}

It is widely accepted method of accessing product performance without the need for physical building and testing. It also shortens prototype development cycle times

$\&$ facilitates quicker product launch. FEA consists of a computer model of a material or design that is loaded and analyzed for specific results. It is used in new product design, and existing product refinement.

\section{Advantages of FEA}

1.The inherent advantages of finite element analysis are as under:

2.Easy to model irregularshapes

3.Possible to evaluate different materials

4.Can apply general load conditions

5.Large numbers and kinds of boundary conditions are possible in FEA

6.Different sizes of elements can be used where necessary

\section{Cheap and easy}

8.Dynamic effects, nonlinear behaviors and nonlinear materials can be examined

9.Reduce the number of prototypes required in the design process

\section{DESIGN CONSIDERATIONS}

All gear parameters are taken from the vertical milling machine gear box of HMT milling machine to achieve high torque for drilling conversion. All gears and gear ratios are standard of HMT vertical milling machine and the other 
Table 1: Motor Shaft Gear

\begin{tabular}{|c|c|c|c|}
\hline SYMBOL & VALUE & UNIT & TERM \\
\hline & $\begin{array}{l}\text { Coarse Pitch } \quad \text { Involute } 20 \\
\text { deg }\end{array}$ & & Standard-Module \\
\hline $\mathrm{Pd}$ & 6.3500 & & Diametral Pitch \\
\hline $\mathrm{m}$ & 4.0000 & & Modular Pitch \\
\hline$\varnothing$ & 20.0000 & deg & Pressure Angle \\
\hline $\mathrm{mg}$ & 2.7778 & & Ratio, 1:x \\
\hline $\mathrm{C}$ & 136.0000 & $\mathrm{~mm}$ & Center Distance \\
\hline MA & 10.3600 & $\mathrm{~mm}$ & Approach Length \\
\hline MR & 9.0321 & $\mathrm{~mm}$ & Recess Length \\
\hline $\mathrm{mp}$ & 1.6422 & & Contact Ratio \\
\hline \multicolumn{4}{|l|}{ GEAR } \\
\hline $\mathrm{Ng}$ & 50.0000 & & Number of Teeth \\
\hline$\overline{D g}$ & 200.0000 & $\mathrm{~mm}$ & Pitch Diameter \\
\hline Do & 208.0000 & $\mathrm{~mm}$ & Major Diameter \\
\hline Dr & 190.0000 & $\mathrm{~mm}$ & Minor Diameter \\
\hline$\overline{\mathrm{A}}$ & 4.0000 & $\mathrm{~mm}$ & Addendum \\
\hline \multirow[t]{3}{*}{$\mathrm{B}$} & 5.0000 & $\mathrm{~mm}$ & Dedendum \\
\hline & 0.0000 & & Addendum Modification Coefficient \\
\hline & 0.0000 & $\mathrm{~mm}$ & Addendum Modification \\
\hline $\mathrm{Db}$ & 187.9385 & $\mathrm{~mm}$ & Base Diameter \\
\hline ht & 9.0000 & $\mathrm{~mm}$ & Whole Depth \\
\hline \multirow[t]{2}{*}{$\mathrm{P}$} & 12.5664 & $\mathrm{~mm}$ & Circular Pitch \\
\hline & 1.2000 & $\mathrm{~mm}$ & Fillet Radius \\
\hline $\mathrm{B}$ & 0.0000 & $\mathrm{~mm}$ & Backlash \\
\hline $\mathrm{T}$ & 6.2832 & $\mathrm{~mm}$ & Tooth Thickness \\
\hline \multirow[t]{2}{*}{$\bar{F}$} & 25.0000 & $\mathrm{~mm}$ & Face Width \\
\hline & & & Size Between Pins \\
\hline $\mathrm{dw}$ & 6.9120 & $\mathrm{~mm}$ & Pin Diameter \\
\hline \multirow[t]{7}{*}{ M } & 209.7168 & $\mathrm{~mm}$ & Measurement Over Pins \\
\hline & & & Chordal Over Teeth \\
\hline & 6.0000 & & Number of Teeth to Gage Over \\
\hline & 67.7480 & $\mathrm{~mm}$ & Chordal Measurement \\
\hline & & & AGMA Quality Class \\
\hline & 0.0000 & $\mathrm{~mm}$ & Max Runout \\
\hline & 0.0000 & $\mathrm{~mm}$ & Pitch Variation \\
\hline
\end{tabular}




\begin{tabular}{|l|l|l|l|} 
& & & \\
\hline & 0.0000 & $\mathrm{~mm}$ & Profile Tolerance \\
\hline
\end{tabular}

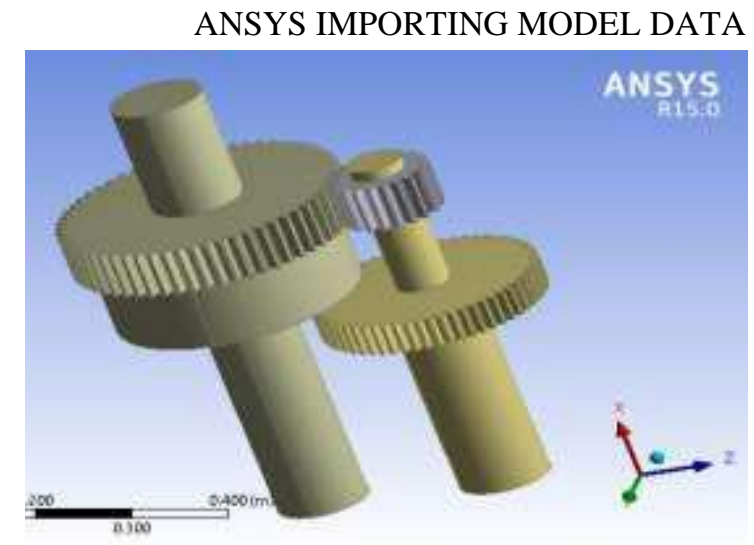

3D assembly model of gears

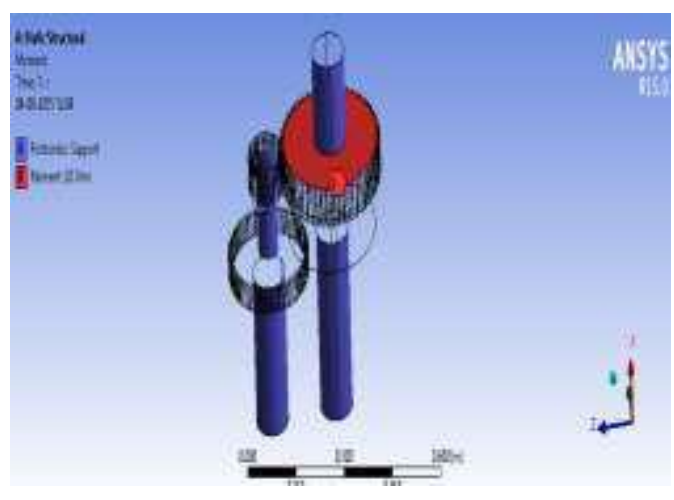

Boundary conditions for single gear system

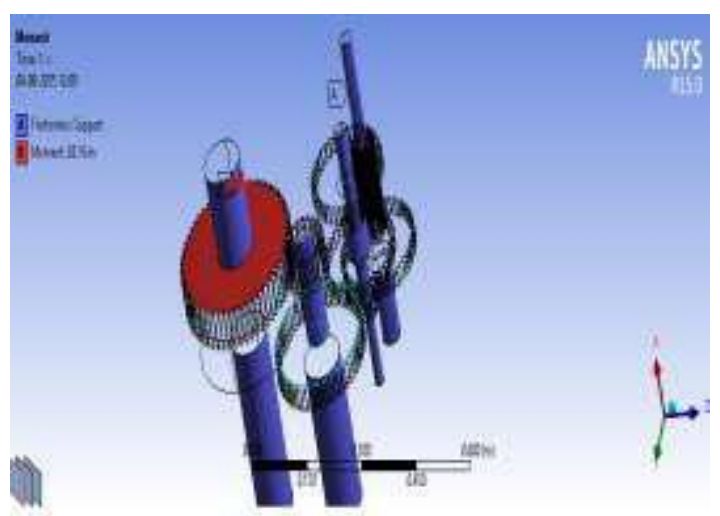

Boundary conditions for assembly gear system

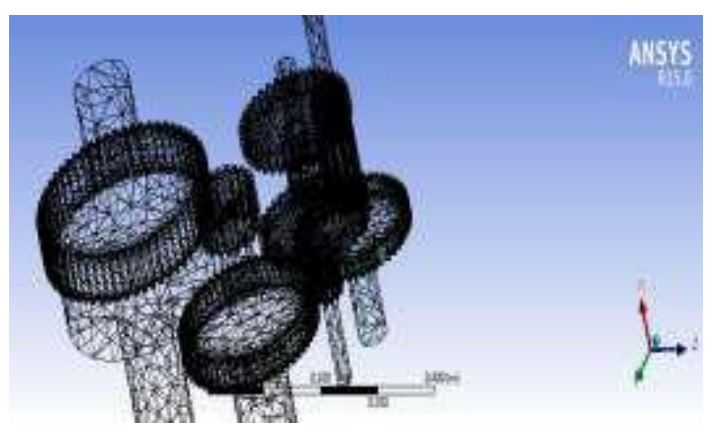

Meshed Model of gear assembly

\section{RESULTS AND DISCUSSIONS}

The below figure shows the equivalent stresses acting on the contact edge of the gears maximum of $2.425 \mathrm{e}-6 \mathrm{~Pa}$ was found on the edge.

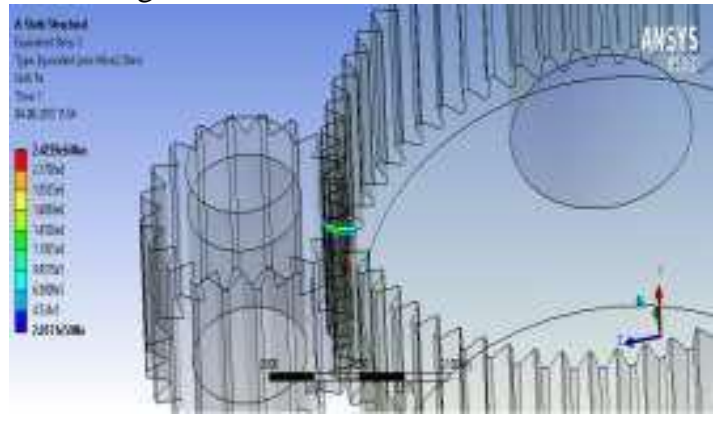

Vonmisses stress using probe

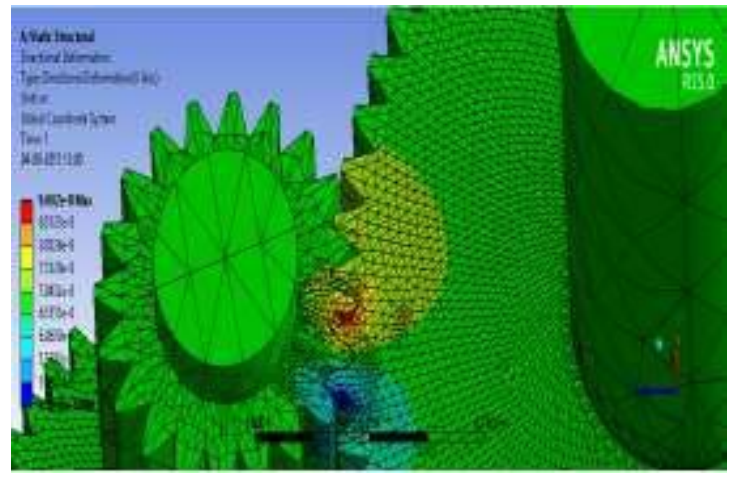

Directional deformation along $\mathrm{x}$ axis 
TORQUE CALCULATION TABLE

VECTOR DUAL DRIVE 20HP \& 10000RPM MAXIMUM

\begin{tabular}{|c|c|c|c|c|c|}
\hline S.No & Speed Rpm & Torque & Torque Used For & $\begin{array}{l}\text { Drilling M/C } \\
\text { Actuals }\end{array}$ & Milling M/C \\
\hline 1 & 500 & 71.2 & Drilling & 74 & NA \\
\hline 2 & 1000 & 68.15 & Drilling & 69.4 & NA \\
\hline 3 & 1500 & 64 & Drilling & 65.2 & NA \\
\hline 4 & 2000 & 61.8 & Drilling/Mill & 63.1 & 53 \\
\hline 5 & 2500 & 58.15 & Drilling/Mill & 59 & 51.2 \\
\hline 6 & 3000 & 54 & Drilling/Mill & 55 & 49 \\
\hline 7 & 3500 & 50.6 & Mill & NA & 46.5 \\
\hline 8 & 4000 & 47.2 & Mill & NA & 43 \\
\hline 9 & 4500 & 44 & Mill & NA & 41.5 \\
\hline 10 & 5000 & 41 & Mill & NA & 38 \\
\hline 11 & 5500 & 39.1 & Mill & NA & 36 \\
\hline 12 & 6000 & 35 & Mill & NA & 32.3 \\
\hline 13 & 6500 & 31.2 & Mill & NA & 28.6 \\
\hline 14 & 7000 & 28 & Mill & NA & 25.1 \\
\hline 15 & 7500 & 25 & Mill & NA & 22.6 \\
\hline 16 & 8000 & 22.5 & Mill & NA & 21 \\
\hline 17 & 8500 & 20 & Mill & NA & 19.2 \\
\hline 18 & 9000 & 19 & \begin{tabular}{|l|} 
Mill \\
\end{tabular} & NA & 18 \\
\hline
\end{tabular}

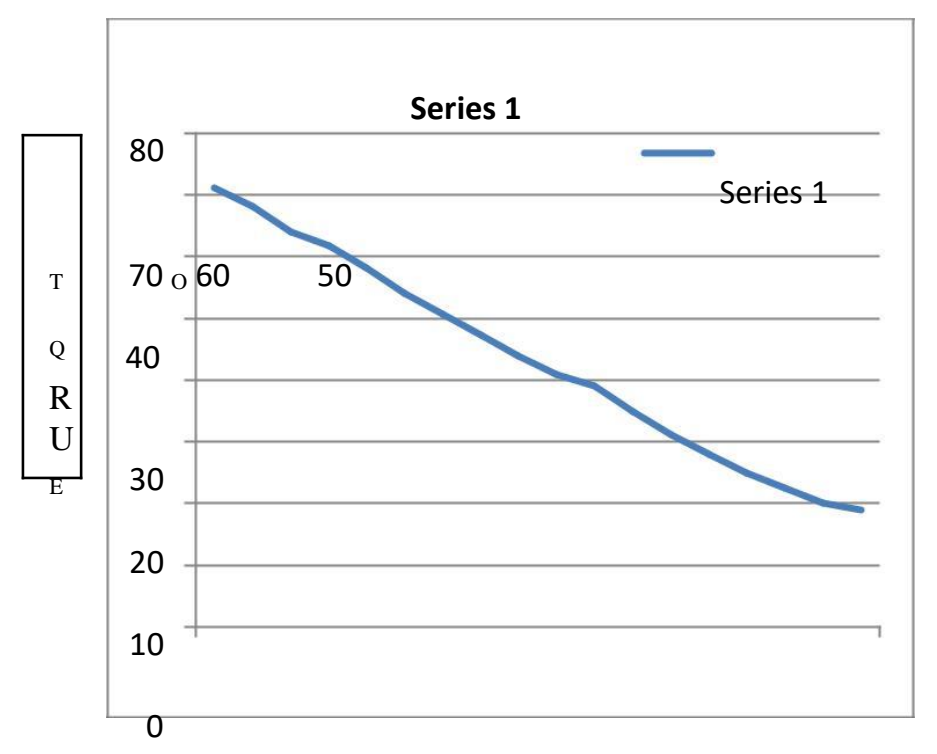

SPINDLE RPM

CONCLUSIONS AND FUTURE SCOPE Torque calculations shows the different torques generates after aligning different gears .Operations of milling and drilling both are operated at the time of changing gear alignment. For the torque changing requirements for drilling and milling shifter shaft has been introduced to change the torque for both operations.

Torque is analyzed by finite element analysis by using ANSYS work bench 15.0. The values and graphs obtained by analysis shows that the deformation with the shifter is very less and the torque generated with attachment of shifter gear is high and when it is disconnected torque is low for milling operation. This project shows an edge for both the operations which is useful for production

50015002500350045005500650075008500 


\section{REFERENCES}

[1] Howard, I., Jia, S., 2001, "The Dynamic Modeling of Spur Gear in Mesh Including Friction and ACrack", Mechanical System andSignal Processing 15(5), 831-853.

[2] Lim, T. C., 1991, "VibrationTransmission through Rolling Element Bearings, Part III : Geared Rotor System Studies”, Journal of Sound and Vibration, 153(1), pp 31-54.

[3] Klenz, S. R., 1999, "Finite Element Analyses of A Spur Gear Set", M.Sc.

[4] Thesis,Dept.ofMechanical Engineering, University of Saskatchewan.
[5] Randall, S. D., Kelly, D.W., "Modeling of spur gear mesh stiffness and static transmission error" , Proc Instn Mech Engrs Vol 212 Part C pp.287-297

[6] Mark, W. D., 1978, "Analysis of the vibratory excitation of gear system: Basic theory”, J. Acoust. Soc. Am., 63, 1409-1430.

[7] Kasuba R., Evans, J. W. 1981, “An Extended Model for Determining Dynamic Loads in Spur Gearing"

[8] Sirichai, S. et al 1997, "Finite Element Analysis of gears in Mesh", Fifth International Congress on Sound and Vibration, Australia, pp 869-876. 